\title{
Studies in the Morphology and Anatomy of the Ophioglossaceae.
}

\author{
II. On the Embryo of Helminthostachys.
}

BY

\author{
WILLIAM H. LANG, M.B., D.Sc., F.R.S. \\ Barker Professor of Cryptogamic Botany in the University of Manchester.
}

With Plate III and nine Figures in the Text.

THE embryology of the Ophioglossaceae ${ }^{1}$ is of peculiar interest on 1 account of the variety in type of embryo within the group. The developmental story is pretty fully known for Botrychium lunaria and $B$. virginianum, in which the embryo has no suspensor, and the salient facts are recorded for $B$. obliqum, in which a suspensor was discovered by Mr. Lyon. For Ophioglossum the embryology is known in O. vulgatum, $O$. moluccanum, and $O$. pendulum. The embryos of these species, while agreeing in having no suspensor, exhibit considerable differences in detail. The present paper is concerned with the embryology in the third genus of Ophioglossaceae, and is thus supplementary to a paper published in this Journal in 1902, which dealt with the prothallus and young plants of Helminthostachys zeylanica.

In my earlier paper no attempt was made to deal with the embryogeny since the material seemed so inadequate. One section of a mature embryo was figured and briefly described, and it was remarked with regard to the earlier stages, 'A number of archegonia had apparently been simultaneously fertilized on a few of the prothalli which were attached to young plants. The preservation of the arrested embryos, which were present in addition to the plant, was not good enough to make a study of the segmentation possible. It was, however, clear that, as in Botrychium, the embryo soon becomes deeply seated.' ${ }^{2}$ The similarity of these young arrested embryos to the young embryos of Botrychium obliquum figured by Bower ${ }^{3}$ from Mr. Lyon's preparations suggested that the embryo of Helminthostachys

1 The recent full summaries and discussions of the facts by Prof. Bower (Land Flora, I908) and Prof. Campbell (The Eusporangiatae, I9II) make detailed reference to the literature unnecessary.

2 Lang, Ann. of Bot., xvi, I902, p. 40.

3 Land Flora, Fig. 266, p. 472.

[Annals of Botany, Vol. XXVIII. No. CIX. January, 1914.] 
also might have a suspensor. The study of a number of series of sections through young plants attached to prothalli established the existence of a well-developed suspensor in Helminthostachys; this was recorded in a brief preliminary note. ${ }^{1}$ These additional series also provided two embryos of intermediate age which were present alongside successful plants.

It is obviously desirable that the embryogeny of Helminthostachys should be fully worked out on normal and adequate material. My material was collected in the Barrawa Forest Reserve in Ceylon in the month of March, after the annual inundation of the forest had subsided. All the female prothalli found bore young plants or mature embryos. Since Campbell's experience in the same locality in February, 1906, was similar, no unfertilized prothalli being found, his inference ${ }^{2}$ that there is an annual periodicity in the development of the prothallus of Helminthostachys seems highly probable. The prothalli probably grow from the spores shed in the previous season, and are fertilized at maturity, the young plants developing forthwith and the prothalli perishing. Under the peculiar conditions that obtain in this locality the collection of a full series of prothalli and embryos may be a matter of great difficulty, and it seems advisable to publish the results obtained from the study of the imperfect material at my disposal. The main features of the embryogeny will therefore be described in this paper, and the form of the young plant followed until the horizontally growing rhizome is established. The consideration of the vascular anatomy will be deferred until the next number of these studies.

Before considering the early stages in the embryogeny it may be well to point out that in the advanced embryo three tiers or regions can be distinguished. The tier next the archegonial neck will be referred to as the upper tier of the suspensor; it often remains as a large undivided cell. The next tier also takes no part in the formation of the embryo proper and will be spoken of as the second tier of the suspensor. The third tier gives rise to the organs of the embryo plant and is comparable to the whole embryo in those Ophioglossaceae that have no suspensor. The embryo proper can be distinguished into a hypobasal half adjoining the suspensor and an epibasal half occupying originally the end of the embryo furthest from the archegonium. It will be shown that the large foot is formed from the hypobasal half, while the stem-apex, first leaf, and probably also the first root, all arise from the epibasal half. The two tiers of the suspensor $\left(s^{1}, s^{2}\right)$ in relation to the young plant or embryo are seen in Pl. III, Photos. Io and I2. This anticipation of the organization of the mature embryo will make the significance of the younger stages clearer as they are described in order.

The very young embryos were in almost all cases more or less contracted or broken down; the limits of the cavity, in which the embryo 
was contained, served however to indicate its shape and its relation to the archegonial venter in which the fertilized egg originally lay. Such a young arrested embryo as is shown in Pl. III, Photo. I may be compared with Bower's figures of the young embryo of Botrychium obliquum. The wider end next the surface of the prothallus marks the position of the enlarged archegonial venter; the still undivided embryo has broken through the lower limit of this and is extending deeper into the prothallus. The embryo shown in Photo. 2 was somewhat older when its growth was arrested; its position in the prothallus is seen in Photo. 4 at $e^{3}$. In this case also the position of the archegonial venter is recognizable above, but the embryo had extended more deeply into the prothallus. The tissues of the embryo are broken down, but the mass in the lower end of the cavity showed the presence of a number of nuclei, and represented the embryo

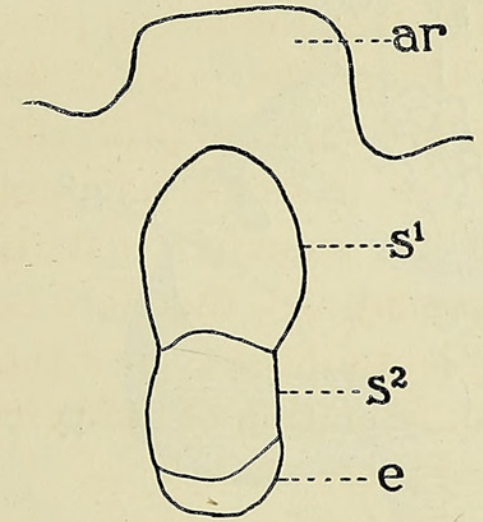

I.

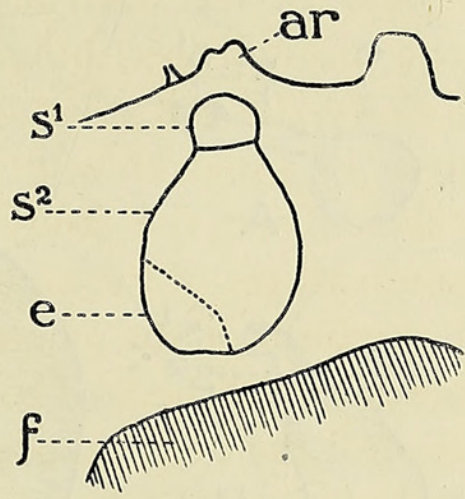

2.

TeXT-FIG. I. Young afrested embryo consisting of three cells in longitudinal section. ar, archegonial neck; $s^{1}$, upper tier of suspensor; $s^{2}$, second tier of suspensor; $e$, the embryo proper. $\times 200$.

Text-Fig. 2. Older arrested embryo cut horizontally. $f$, foot of the plant borne on the same prothallus; ar, archegonial neck above the embryo; $s^{1}$, upper tier of suspensor; $s^{2}$, lower tier; $e$, embryo proper. The broken-down tissues of the embryo are not indicated. $\times 5^{\circ}$.

proper. Segmentation had thus considerably advanced before this embryo perished. The walls separating the three tiers of the embryo $\left(s^{1}, s^{2}, e\right)$ were not preserved. They are shown, however, in Text-fig. I, which represents an embryo intermediate in age between those in Photos. 1 and 2. It is unnecessary to go further into the features of these very young arrested embryos, a considerable number of which were studied. They showed the similarity of the early stage of development to Botrychium obliquum, and they indicate that the region of the suspensor is distinguished from the rest of the embryo at an early period, but they do not justify inferences as to the early stages of segmentation of the embryo proper.

The older arrested embryo, a horizontal section through which is represented in Text-fig. 2, showed the upper tier of the suspensor marked off by a thick wall from the second tier, while the limit between the terminal 
tier destined to develop into the embryo proper and the second tier of the suspensor was evident though not so strongly marked; the terminal tier was more developed in the next lower section which missed the upper tier of the suspensor. The preservation of the tissues of this embryo was not sufficiently good to allow of detailed representation, but the outline is given because it affords a truer idea of the shape of the embryo at this stage than does the slightly more advanced embryo next to be described.

The first of the two well-preserved embryos of intermediate age had an abnormally long second tier to its suspensor. This had carried the embryo proper into the cavity in the prothallus occupied by the base of the successful plant. The transverse sections of the prothallus cut the embryo horizontally, and, since the latter extended downwards and inwards into the prothallus, an idea of its shape and construction as a whole could only
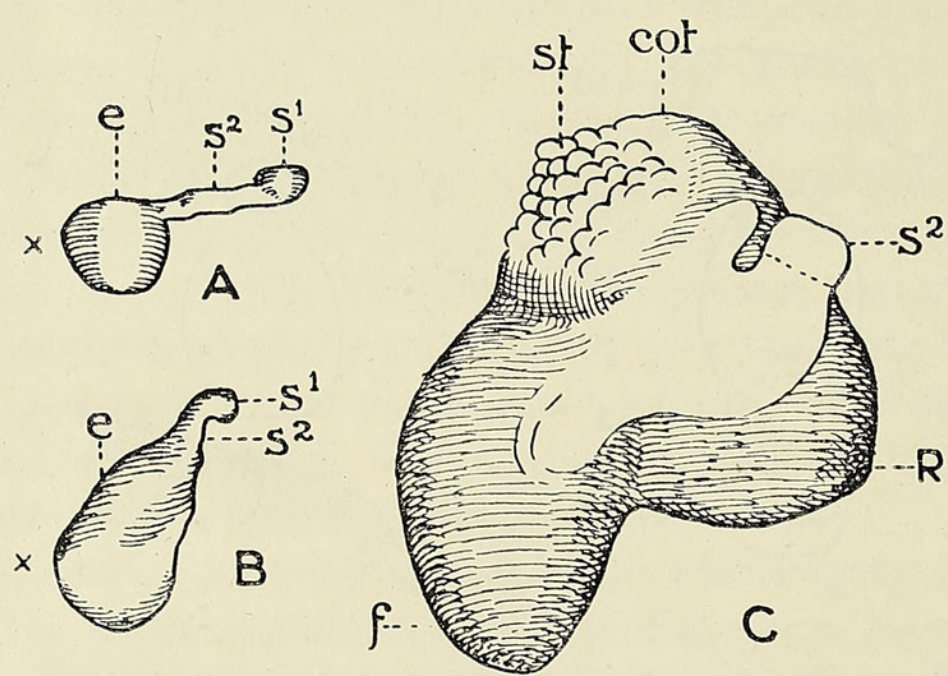

TEXT-FIG. 3. Outline figures of reconstructions of three embryos. $\times$ about 30 diameters. $A$, the smaller intermediate embryo seen from the side. B, the larger intermediate embryo seen from the side. $s^{1}$, upper tier of suspensor; $s^{2}$, lower tier ; $e$, embryo proper. The cross is opposite the apex of the shoot. C, mature embryo seen from the side on which the suspensor is attached. $s^{2}$, suspensor; $f$, foot; $r$, root ; cot, first leaf; st, position of apex of stem covered by hairs.

be obtained by combining the information obtained from the successive sections. Text-fig. 3 , A shows the shape of the embryo as given by a model constructed to scale, the embryo being seen from the side, while outline figures of a number of the sections of the region of the prothallus containing the embryo are given in Text-fig. 4. Two of the sections are also represented in Pl. III, Photos. 3 and 4. As the latter photograph shows, the prothallus bore a well-developed plant $\left(e^{1}\right)$, the embryo under consideration $\left(e^{2}\right)$, and the younger arrested embryo already described $\left(e^{3}\right)$. The embryo of intermediate age is seen in Text-fig. 4, B-F. In B the large cell forming the upper tier of the suspensor $\left(s^{1}\right)$ is seen cut obliquely, but the level of the section is still above the rest of the embryo. In $\mathrm{C}$ the lower portion of this cell is still seen $\left(s^{1}\right)$, and continuing obliquely downwards and inwards from it is a row of cells corresponding to the elongated second tier of the 
suspensor $\left(s^{2}\right)$. In D the lower end of the suspensor $\left(s^{2}\right)$ is seen to be continuous with an oval mass of cells belonging to the embryo proper $(e 2)$, and the following sections only show this, their level being below that of the suspensor. At the level passed through in $\mathrm{E}$ the embryo proper is seen to consist of two tiers, the limit between which is indicated by the dotted line. Still lower sections (F) miss the terminal or epibasal tier of the embryo and indicate that the hypobasal tier bulges downwards. If the figure of the reconstructed embryo (Text-fig. 3, A) is considered in the light of the separate sections it will be clear that it consists of the upper tier of the suspensor $\left(s^{1}\right)$, composed of a single large

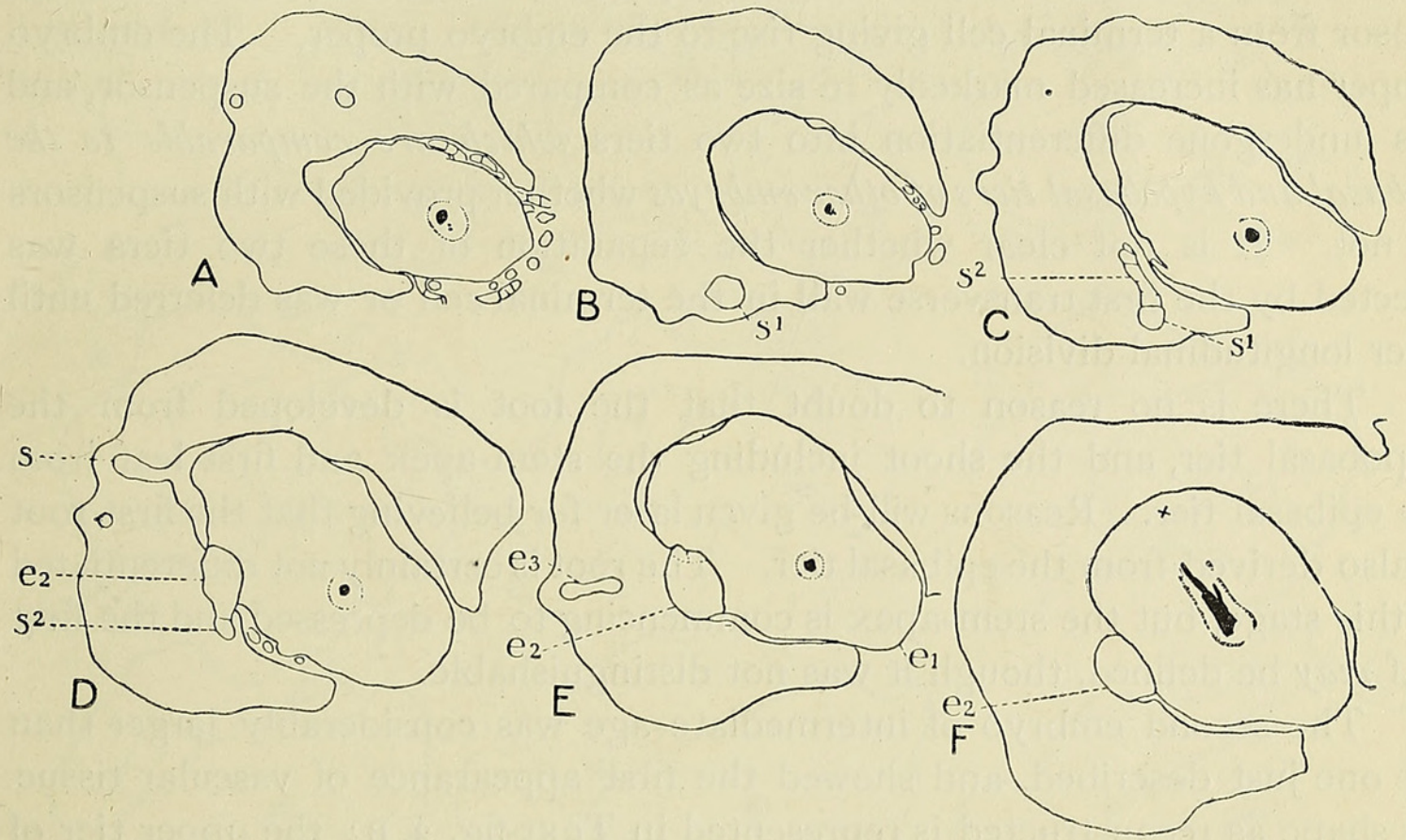

TEXT-FIG. 4. Outline figures of a number of transverse sections of a prothallus bearing a young plant $(e \mathbf{I})$; an embryo of intermediate age $(e 2)$; and a young arrested embryo $(e 3) \cdot s^{1}, s^{2}$, first and second tiers of the intermediate embryo; $e 2$, the embryo proper. $s$, the cavity once occupied by the suspensor of the plant. $\quad x$ in $F$, position of root apex of the plant.

cell ; of the second tier of the suspensor $\left(s^{2}\right)$, which in this specimen is much elongated and composed for the most part of a row of cells; and of the globular embryo itself $(e)$, which is enlarged downwards where the foot is developing. The epibasal tier with the apical region is opposite the cross, and it will be evident that the embryo is as yet straight in that the epibasal tier is not directed upwards.

Pl. III, Photo. 3 shows the appearance of the elongated suspensor $\left(s^{1}, s^{2}\right)$, while Photo. 4 is of a section passing through the embryo proper $\left(e^{2}\right)$ at a level which traverses both the hypobasal and epibasal tiers. A similar section of the embryo is seen more highly magnified in Photo. 5. As this shows, the lower or hypobasal tier (hyp.) is composed of larger cells not presenting a meristematic appearance, while the small terminal tier $(e p$. 
contrasts with it in the meristematic character of its densely stained cells. Although the initial cell of the stem could not be distinguished with certainty, it is clear that the embryo of Helminthostachys conforms to and supports Bower's generalization that the apex of the shoot is initiated close to the centre of the epibasal pole.

From this single specimen it is not possible to speak with certainty as to the segmentation of the embryo, but careful study suggests the following interpretation, which is consistent with the appearances presented by both younger and older embryos. The first transverse wall evidently separated the cell forming the upper tier of the suspensor from the rest of the embryo. The next wall was also transverse and separated the second tier of the suspensor from a terminal cell giving rise to the embryo proper. The embryo proper has increased markedly in size as compared with the suspensor, and has undergone differentiation into two tiers which are comparable to the epibasal and hypobasal tiers of other embryos whether provided with suspensors or not. It is not clear whether the separation of these two tiers was effected by the first transverse wall in the terminal cell or was deferred until after longitudinal division.

There is no reason to doubt that the foot is developed from the hypobasal tier, and the shoot including the stem-apex and first leaf from the epibasal tier. Reasons will be given later for believing that the first root is also derived from the epibasal tier. The root is certainly not differentiated at this stage, but the stem-apex is commencing to be depressed and the first leaf may be defined, though it was not distinguishable.

The second embryo of intermediate age was considerably larger than the one just described, and showed the first appearance of vascular tissue. Its shape as reconstructed is represented in Text-fig. 3, B; the upper tier of the suspensor $\left(s^{1}\right)$ consisted of a single large cell, the second tier $\left(s^{2}\right)$ was not unduly elongated as in the preceding example, and widened gradually towards the embryo proper. Both tiers of the latter had contributed to the enlargement of the embryo, but the apex is still not directed upwards, its position being indicated by the cross.

The position of the embryo in the prothallus, which also bore a welldeveloped plant, and the plane in which the embryo was cut will be evident from Text-fig. 5. The plane of section in this case was practically at right angles to the long axis of the embryo. Starting from the back of the embryo below the remains of the archegonial neck, the series first showed the large cell forming the upper tier of the suspensor (Text-fig. 5, A, $s^{1}$ ). This joined on at the lower end to the second tier of the suspensor $\left(s^{2}\right)$, which was composed of a tissue of rather large cells and widened gradually to its junction with the base of the embryo proper $(e)$. The second tier of the suspensor is seen in $\mathrm{B}$ joining on to the lower end of the upper tier; in $\mathrm{C}$ the second tier of the suspensor is seen above, while below it the section 
passes through the posterior portion of the embryo proper. Still further forward (D) only the anterior and upper edge of the suspensor is cut by the section, the main part of which passes through the hypobasal tier of the embryo. The section in $\mathrm{E}$ traverses the anterior portion of the hypobasal tier, the cells bounding the lower surface of which had the characteristic appearance of the absorbent epithelium of the foot. The arrangement of the cells in the region marked with a cross suggested that the section here passes through the apex of the primary root. A section a little further forward (F) shows (immediately above the presumable position of the root-
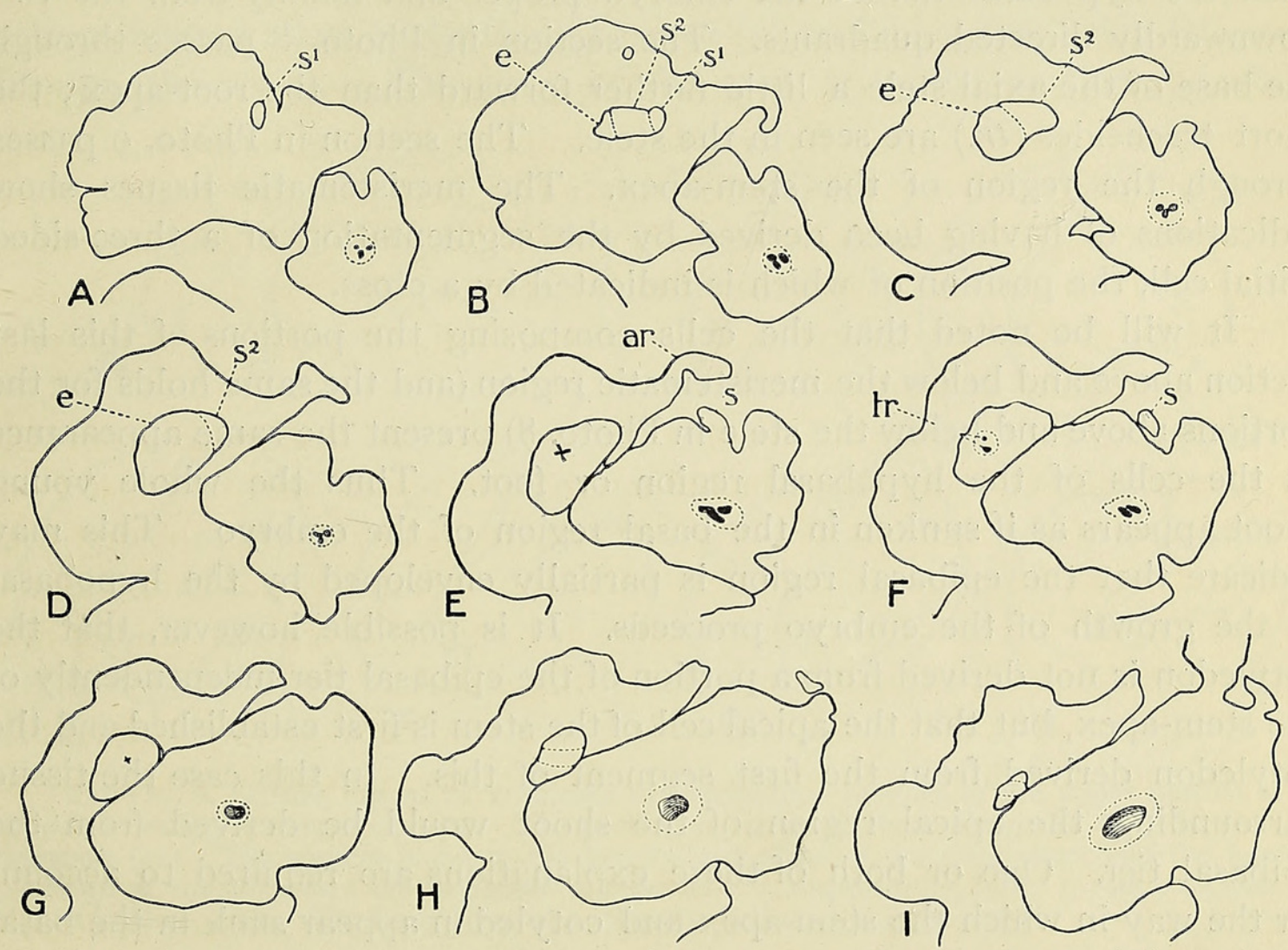

TEXT-FIG. 5. Outline figures of a number of longitudinal sections of the upper portion of a prothallus bearing a young plant and an embryo of intermediate age. The susperisor of the plant is seen at $s$ in $\mathrm{E}$, while the corresponding archegonium is seen at $a r$. $s^{1}$, first tier of suspensor of the intermediate embryo; $s^{2}$, second tier of suspensor; $e$, base of embryo proper; $\times$ in $\mathbf{E}$ marks position of the apex of the root ; $\operatorname{tr}$ in $\mathrm{F}$ the tracheides developed in the stele; $x$ in $\mathrm{G}$ the position of the apex of the stem.

apex) a desmogen strand, in which a few short tracheides are lignified. Still further forward $(G)$ the apical region of the shoot marked with a cross is cut through. The portion of the next two sections marked off by the dotted lines corresponds to the young cotyledon or first leaf bent closely over the stem-apex.

The detailed structure of four sections of this embryo is shown in Photos. 6-9. It would have been difficult to make detailed drawings of this poorly stained embryo without either over-emphasizing the indications of segmentation which it affords, or on the other hand missing these indica- 
tions, so that in this case photographs afford the best representation possible. The section in Photo. 6 passes through the second tier of the suspensor $\left(s^{2}\right)$ and the hindmost portion of the hypobasal tier of the embryo $(e)$; the distinction between the two regions is brought out by the difference in size and appearance of the cells composing them. The section in Photo. 7 passes through the hypobasal tier of the embryo proper. It seems clear that the lower half of this (i. e. the two downwardly directed quadrants) has developed more than the upper half. The cells of the lower half have the characteristic appearance of cells of the foot. The foot thus appears to be developed from the hypobasal tier of the embryo proper and mainly from the two downwardly directed quadrants. The section in Photo. 8 passes through the base of the axial stele a little further forward than the root-apex; the short tracheides $(t r$.$) are seen in the stele. The section in Photo. 9$ passes through the region of the stem-apex. The meristematic tissues show indications of having been derived by the segmentation of a three-sided initial cell, the position of which is indicated by a cross.

It will be noted that the cells composing the portions of this last section above and below the meristematic region (and the same holds for the portions above and below the stele in Photo. 8) present the same appearance as the cells of the hypobasal region or foot. Thus the whole young shoot appears as if sunken in the basal region of the embryo. This may indicate that the epibasal region is partially enveloped by the hypobasal as the growth of the embryo proceeds. It is possible, however, that the cotyledon is not derived from a portion of the epibasal tier independently of the stem-apex, but that the apical cell of the stem is first established and the cotyledon derived from the first segment of this. In this case the tissue surrounding the apical region of the shoot would be derived from the epibasal tier. One or both of these explanations are required to account for the way in which the stem-apex and cotyledon appear sunk in the basal portion of the embryo.

Four prothalli ${ }^{1}$ were obtained with large normal embryos ready to grow further into young plants. These prothalli were cut into series of longitudinal sections, but this did not result in cutting the embryos in any definite corresponding plane. The embryos were all cut more or less obliquely, so that their interpretation from isolated sections was difficult. The most readily understood specimen was that of which a section is figured in my earlier paper. ${ }^{2}$ This section, longitudinal as regards the embryo proper, was approximately median for the young shoot which was directed upwards. It passed through the stem-apex, which was overhung by the first leaf. Below the first leaf was the bulge of the young root, while on the other side the large foot bulged into the prothallus. The relative 
positions of these organs is also seen in the accompanying outline figure (Text-fig. 6, F). While, as stated in my earlier paper, the relative position of the primary organs of the embryo appears to be the same as is described for the embryo of Botrychium virginianum, an essential difference comes out when all the sections of the series are considered, and especially when the embryo is reconstructed. A number of sections of the series are represented in Text-fig. 6. The plane of section had passed at right angles to the insertion of the suspensor, which was somewhat flattened by the expansion of the embryo. The suspensor, probably the lower tier, is seen in Text-fig. $6, \mathrm{~A}$ and B at $s$. From it the embryo widened out suddenly, and the other sections figured allow of the foot $(f)$, root $(r)$, and shoot $(s h)$ being followed through the series. The apex of the root is in the section $\mathrm{D}$, while

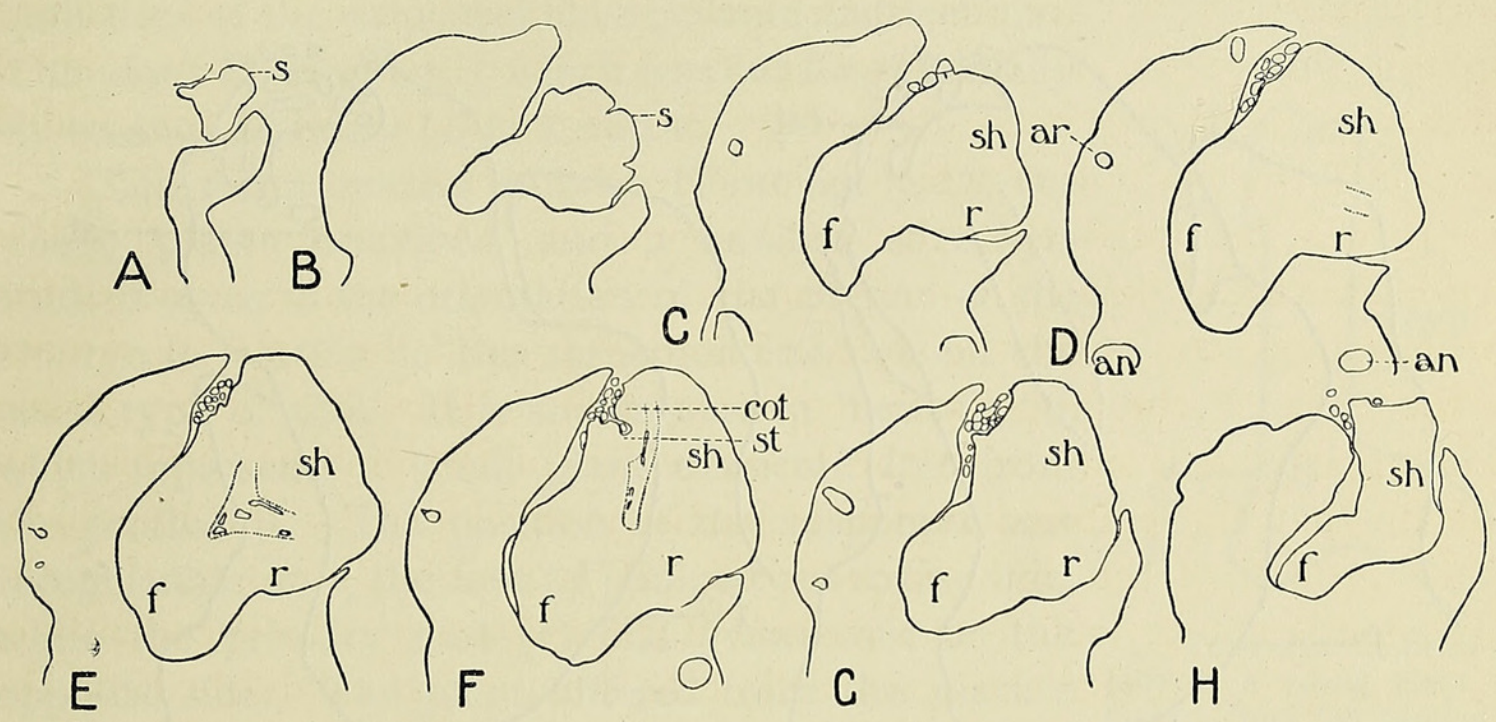

Text-FIG. 6. Outline figures of a number of longitudinal sections of the upper portion of a prothallus bearing a mature embryo. The prothallus, as usual, bore antheridia (an) as well as archegonia (ar). The embryo is cut in the longitudinal plane of the erect shoot and the figures commence at the side where the suspensor is attached. s, suspensor; $f$, foot; $r$, root ; sh, shoot ; cot, first leaf; st, stem. The central vascular system is indicated in D, E, and F.

the cotyledon $(c o t)$ and the apex of the stem $(s t)$ are distinguishable in $\mathrm{F}$, which is median for the upwardly directed shoot. The position of the vascular strand in the shoot and root can be gathered from the sections in $\mathrm{D}, \mathrm{E}$, and $\mathrm{F}$.

The reconstructed embryo seen from the suspensor side is represented in Text-fig. 3, C. It shows the suspensor $(s)$ and the result of development of the embryo proper. The great difference from the smaller embryos described is that the shoot with further growth has become vertical. The position of the first leaf $(\cot )$ and of the stem-apex $(s t)$ are indicated, as well as the development of hairs over the apical region. The root $(r)$ has grown downwards and towards the side away from the mass of the prothallus, while the large foot $(f)$ has extended into the latter. Comparison of the three embryos in Text-fig. 3 will show what a considerable readjustment 
must have taken place, as the embryo not only grew but changed the direction of growth of the shoot. This readjustment has led to the similarity in position of the organs to the embryo of Botrychium virginianum, though the latter is inverted from the commencement of development and has no suspensor.

The reconstruction not only explained the organization of this embryo, but enabled the other series through embryos of corresponding age to be interpreted. Thus the two sections figured in outline in Text-fig. 7 are from an approximately longitudinal series in a plane at right angles to that of the series in Text-fig. 6 . The first section includes the stele and the trace to the first leaf or cotyledon, the second shows the tip of the cotyledon bent over the stem-apex. These sections are figured, because they afford a further illustration of the way in which the shoot-apex, including the

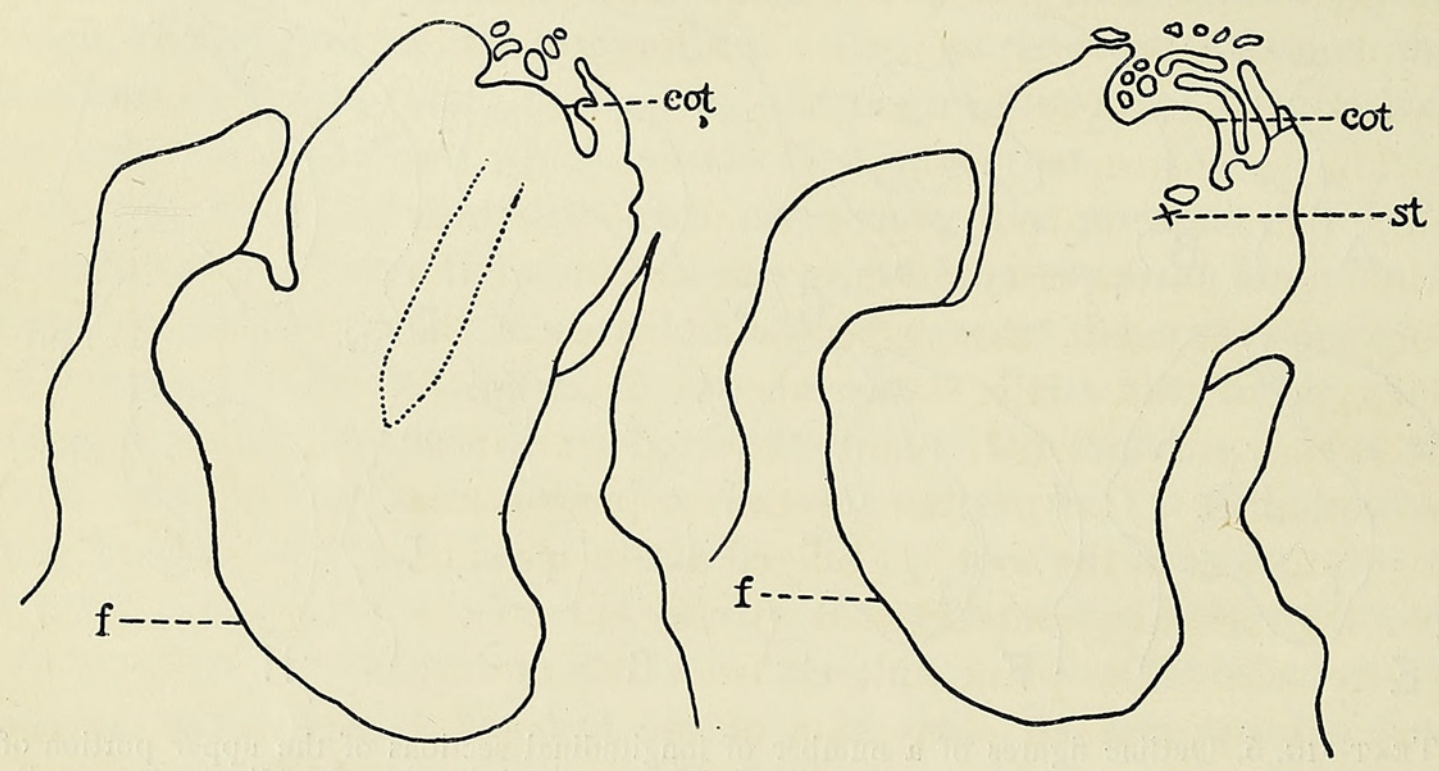

TEXT-FIG. 7. Outline figures of two sections through another mature embryo. $f$, foot; cot, first leaf; $s t$, apex of stem. The apex of the shoot is surrounded by a rim of tissue-bearing hairs.

cotyledon, is sunk in the summit of the embryo. ${ }^{1}$ The surrounding rim of tissue bears numerous multicellular hairs.

The section represented in Pl. III, Photo. IO was from another series, which cut the embryo in an obliquely transverse plane. Its interest lies in the fact that it cut the perfectly preserved suspensor longitudinally. A photograph on a larger scale of the suspensor is shown in Plate III, Photo. II. The suspensor is seen to consist of the upper tier $\left(s^{1}\right)$, composed of a large cell, in which, however, a few divisions had taken place, and of the lower multicellular tier $\left(s^{2}\right)$, which widened gradually towards the embryo proper. The two tiers of the suspensor are separated by a thick wall.

The change from mature embryos, such as those just described, to the young plants with an expanded green leaf, such as those figured in my earlier paper, is simply due to further growth of the root and shoot. The 
primary or first root grows out and turns downwards into the soil, while the hypocotyl lengthens, carrying up the cotyledon and the terminal bud. The relations of the basal part of the plant to the prothallus remain unchanged, though the suspensor may be more or less completely broken down. An example of this is afforded by Text-fig. 4, D, where the suspensor of the plant is unrecognizable, although the cavity which it occupied $(s)$ is evident, leading down from the archegonial neck. Pl. III, Photo. I 2 shows a fairly well preserved suspensor in relation to the base of a young plant. The large upper cell of the suspensor was undivided, while the second tier of the suspensor was divided up into cells. The suspensor figured in Pl. III, Photo. $\mathrm{I} 3$ is from another young plant. It is of interest in that it shows the remains of the archegonial neck above (ar) and also because in this case both tiers of the suspensor have become multicellular. The plant in Text-fig. 5 which was cut longitudinally shows the suspensor $(s)$ in $\mathrm{E}$ and $\mathrm{F}$.

The reconstructed embryo (Text-fig. $3, \mathrm{C}$ ), the young plants described, and a number of others studied agree in the orientation of the organs of the embryo in relation to the suspensor and present the usual type of this. It is shown also in Text-fig. 8, which represents a small plant dissected free from the prothallus. The position of the suspensor was recognizable at $s$, the foot $(f)$ bulged out to one side, while the primary root $(r)$ had grown out on the opposite side. The plant differed from the mature embryo in the marked elongation of the hypocotyl $(h y p)$, but the first leaf $(\cot )$ is seen to stand above the first root, while the enlarged apical bud is enclosed by the sheath of the first leaf. Below the bud the second root $\left(r^{2}\right)$ is seen.

The general appearance and external morphology of the young plants have already been described and figured in my earlier paper and also by Campbell. In all the young plants observed by Campbell the first leaf or cotyledon remained rudimentary, and did not come above ground or expand its lamina. I have also met with examples of this behaviour, but in the majority of the young plants I have studied I find that, as described in my earlier paper, the first leaf became fully developed and expanded above ground. I am thus unable to accept Campbell's generalization ${ }^{1}$ that 'it is probable that the cotyledon in Helminthostachys, as in Botrychium lunaria and Ophioglossum vulgatum, is always a rudimentary organ and never appears above ground'. The fact is that it may be either fully developed or more or less arrested, and presumably the former condition is the more primitive. 
In the further growth of the young plant the originally vertical direction of the axis appears to be maintained for a short period, although as regards the position of the leaves on one side of the stem and the roots on the other dorsiventrality is established at once. The dorsiventrality is probably related to the position of the three-sided initial cell. After a few more leaves and roots have been developed, however, the apex changes its direction of growth and bends over; the further growth of the rhizome proceeds horizontally. The change is shown in the outline figure of the larger plant in the accompanying figure (Text-fig. 9, B). In the other plant (Text-fig. 9, A) the axis, so far as it is well developed, had grown vertically, but the tip was curved over and is directed towards the spectator. It will be evident from this specimen that the origin of the plant from an embryo

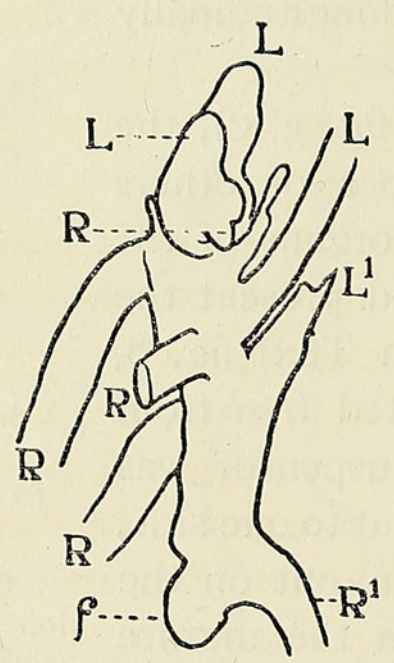

A

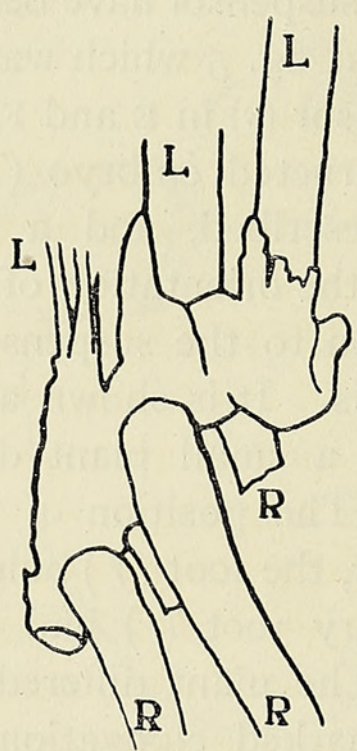

B

TeXT-FIG. 9. A, young plant still showing the foot $(f)$ and the primary root $\left(r^{1}\right)$ at the base. The shoot has grown erect for a time but is now extending horizontally towards the spectator. $\mathrm{B}$, similar plant from the side, showing the change from the vertical to the horizontal rhizome. The foot and primary root have been broken off.

is shown not only by the presence of the foot, but by the different position occupied by the first root to that of all the succeeding ones. The later roots all spring from the ventral side of the rhizome, while the first root stands below the first leaf and apparently on the dorsal side of the rhizome. The significance of this will be discussed later. The second specimen, which shows the change in direction of growth of the rhizome better, also had the foot and first root at its base, but this had unfortunately got broken. off before it was drawn.

\section{Discussion of Results.}

The preceding account of the embryo of Helminthostachys, though incomplete, provides the main facts. It is clear that the first stage of development of the fertilized egg-cell exhibits a definite polarity with the 
apical pole directed inwards, i. e. away from the archegonial neck. Following on this come divisions at right angles to the long axis of the embryo, resulting in a stage in which the embryo consists of a row or filament of three cells. Further divisions may take place in all three cells, but the large cell next the archegonial neck often remains undivided; it forms the upper tier of the suspensor. The next cell undergoes division and usually forms the short and wide second tier of the suspensor; it may, however, take the form of an elongated row of cells. The embryo proper is derived from the third or terminal cell. The divisions in this result in the distinction of a hypobasal half from which the foot is mainly developed, and of an epibasal half in which the apex of the shoot is initiated close to the central point. By further growth of the epibasal half all the primary members of the young plant are laid down, the first leaf developing close to the apex of the stem, while the primary root probably arises endogenously and originally points backwards towards the hypobasal half and the suspensor. The vascular system of the plant is initiated in the axial line between the apex of the shoot and the primary root.

Up to this stage the growth of the embryo would appear to be determined by its position in the prothallus with relation to the archegonial neck, and the axis of the embryo is approximately straight. The further growth to the condition in the mature embryo involves a marked curvature. This is not a simple bending, for the whole embryo is growing at once. It results in the enlarging shoot becoming vertical. The facts do not allow of the full mechanism of this being understood, but two factors must be recognized, both of which probably come into play. On the one hand, there is the great and unequal enlargement of the hypobasal tier giving rise to the foot, which bulges towards and into the prothallus from which nutriment has to be obtained. On the other hand, and possibly more important, is the change in irritability of the growing shoot in relation to gravity; the shoot ceases to grow in the original line of the primary filament of the embryo and grows vertically. Both these factors probably contribute to the changed configuration of the mature embryo. The erect position of the shoot is not attained passively by the enlargement of the foot, but by active growth. On the other hand, the apparently lateral position of the first root is probably the result of the great increase of the hypobasal region on one side in forming the foot. ${ }^{1}$

1 The distinction between two stages in the development of the embryo, the first in which the form and structure is dependent on internal factors and on the correlations between the embryo and the surrounding tissues, and the second in which the direction of growth of the organs is dependent on their reactions to such external stimuli as gravity, is possibly an important one. It may be pointed out that it is seen in the Spermaphytes in (I) the growth of the embryo in the embryo-sac of the developing seed, and (2) the growth of the embryo on the start of germination. In this case the two stages appear separated by the period of rest. In such a case as the embryo of Helminthostachys the two stages are recognizable, but the development goes on without a break. The interesting 
The nature of this complete readjustment of the organs of the embryo of Helminthostachys during the curvature must be borne in mind in comparing it with embryos (such as that of Danaea) in which the axis remains straight throughout development, and the foot shows no marked enlargement.

If the embryo of Helminthostachys is compared with what we know of the embryo of Botrychium obliquum ${ }^{1}$ it will be clear that here also the first direction of development was in a line directly inwards from the archegonial neck, and that later a change in direction of the growth of the embryo proper led to the shoot growing vertically upwards and the root vertically downwards. The root and shoot of the fully grown embryo are in the same straight line, and it is noteworthy that no well-developed foot is described in this plant. With our present imperfect knowledge it must remain an open question whether the suspensor as figured by Lyon has two tiers, and corresponds exactly to the suspensor of Helminthostachys, or whether the second tier in his figure corresponds to the poorly developed hypobasal half of the embryo proper which in Helminthostachys forms the foot.

In the other species of Botrychium and in Ophioglossum there is no suspensor, the embryo is inverted from the first, and the primary distinction is into the hypobasal half directed downwards into the prothallus and forming the more or less marked foot, and the epibasal half directed towards the archegonial neck and forming all the organs of the plant. It is not necessary to enter into detailed comparisons with these forms, and reference may be made to the works of Bower and Campbell cited.

It is difficult to discuss any one peculiar pteridophytic embryo without being led into a general survey of the embryogeny in the phylum. To avoid this the comparative discussion in Chapter XLII of Bower's 'Land Flora' may be assumed as a starting-point. This is the more justifiable, as this chapter may be regarded as the first critical comparative statement on the morphology of the embryo of Pteridophyta.

Professor Bower regards the relation of the apex of the axis to the primary segmentation of the embryo as constant, and the apex of the stem as occupying as nearly as possible the centre of the epibasal hemisphere. Whatever subsequent change in the direction of the apex occurs, the polarity has been determined before, and is indicated by, the first segmentation of the embryo. All further knowledge of particular embryos since the date when Professor Bower made this generalization seems to confirm it, and it appears to state a primary fact.

Within the same phylum, as Professor Bower further points out, examples of embryos with suspensors and embryos without suspensors are physiological problem thus raised is when and how the internal correlative influences between the embryo and the prothallus (or seed) are superseded by this irritability of the parts of the embryo to gravity.

1 Cf. the figures in the Land Flora, pp. 47 I, 472. 
met with. The apical pole of the embryo with a suspensor always points away from the archegonial neck, but the position of embryos without suspensors exhibits differences. The position of the embryo (as compared with embryos with suspensors) may be completely inverted, the epibasal pole being directed towards the archegonial neck instead of away from it. This is the position of the embryo of Equisetum, which has no suspensor. It is found in Isoetes in contrast to the embryos of other Lycopodiales where suspensors are present. In the Ophioglossaceae similarly, and even in the single genus Botrychium, embryos with and without suspensors are met with, and inversion of the polarity of the embryo is associated with the absence of a suspensor. From the evidence afforded by the Lycopodiales and Ophioglossaceae, Bower regards the type of embryo with a suspensor as the more primitive and as having been associated with a bulky prothallus, often subterranean and saprophytic. It appears to be implied, though not actually stated, that the suspensor is here biologically useful in carrying the embryo deeper into the bulky prothallus. The non-development of the suspensor and the associated inversion of the embryo are regarded in both of these groups as having been an advantage in avoiding an ' awkward curvature'. and simplifying 'an awkward and inconvenient process'. The type of embryo without a suspensor is regarded as 'characteristic of stocks with less bulky prothalli, usually above ground and self-nourishing'. Whether a similar progression from embryos with to those without suspensors has taken place in the Filicales (excluding the Ophioglossaceae) and the Equisetales is left an open question by Bower, but the progress from more bulky to less bulky prothalli in the Filicales is regarded as consistent with such an assumption.

Thus we have as further generalizations (in addition to the primary one of the constant position of the apex of the shoot at the centre of the epibasal pole): (a) the probability that the type with suspensor is relatively primitive; $(b)$ that the presence of a suspensor is correlated with more bulky prothalli ; $(c)$ that the loss of the suspensor on inversion of the embryo may be regarded as a biological advantage.

Since the date of publication of the 'Land Flora' our knowledge of the embryology of the Filicales has been increased by a fuller account of the embryos of Marattiaceae (including the embryo of Danaea, ${ }^{1}$ which is provided with a suspensor) and by the main facts for Helminthostachys described in the preceding pages. The existence of forms with and without suspensors in two comparatively narrow circles of affinity, such as the Ophioglossaceae and the Marattiaceae, is of great interest. The interest is increased by the probability that both groups are relatively primitive among the Filicales. It thus appears most profitable to confine this discussion to the Filicales, and to critically consider the generalizations reached by Bower as applied to this phylum. In doing so it will of course be clear that all the facts for

1 Campbell, loc. cit., pp. I 42-6. 
the Filicales we now possess were not before Professor Bower when his views were expressed.

As already indicated, all the additional facts for the Marattiaceae and for Helminthostachys support Bower's primary generalization as to the early determination and constant position of the stem-apex. Some facts also strongly suggest, though proof is wanting, that the first leaf or cotyledon may be derived in some cases from the further growth of the apex of the stem, and not be laid down as a primary member independently of the apical cell of the stem. If this is so the primary importance of the axis would be increased.

The discovery of a suspensor in a second genus of Ophioglossaceae, and also in Danaea among the Marattiaceae, is in favour of Bower's further generalization that the type of embryo with a suspensor may be regarded as relatively primitive. It would seem probable that, while the suspensor had been suppressed in certain Pteridophytes, it was originally present, at least in the Filicales and Lycopodiales.

Critical consideration of the available facts does not, however, appear to me to support the view that the presence or absence of the suspensor is correlated with the bulk of the prothallus, or that it is to be explained on biological grounds. Thus, within the Marattiaceae the prothallus is always fairly massive and green. ${ }^{1}$ The prothallus is least massive in Danaea, and it is in this genus, as Campbell has shown, that the first division in the embryo separates a suspensor from the embryo proper. This is not the case in the other genera where the fertilized ovum gives rise directly to the embryo proper. There is no change in orientation, the axis of the embryo remaining straight, with the shoot-pole turned away from the archegonial neck. On further growth the shoot bursts upwards through the prothallus and the root vertically downwards into the soil. Thus in the Marattiaceae the suspensor seems to be of no particular use, and, on the other hand, the change from an embryo with a suspensor to one without seems to involve no biological advantage and not to stand in any obvious relation to the bulk of the prothallus.

The same result follows if the Ophioglossaceae are considered. Here in all cases the prothalli are relatively bulky and saprophytic. Though, owing to the conformation of the prothallus and the direction of the archegonia, the embryo cannot grow straight upwards through the prothallus as in the Marattiaceae, the available evidence is against regarding the curvature of the embryo as involving any serious disadvantage. It has been shown that it does not prevent the successful growth of the plant in Helminthostachys. The suppression of the suspensor thus does not seem well explained on biological grounds, though it certainly leaves the way

1 The fact that the prothallus contains an endophytic fungus does not appear to be of primary importance as regards the embryogeny. 
open for a new arrangement of the primary polarity of the embryo which may be more satisfactory. A similar rearrangement of polarity is found in the Leptosporangiate Ferns where a suspensor is wanting and the initial polarity of the embryo is different.

Thus, while accepting fully Bower's conclusions as to the importance of the primary polarity of the embryo, and as to the probability of the type of embryo with a suspensor being relatively primitive, it does not seem to me clear, from a consideration of the Marattiaceae and Ophioglossaceae, that the suspensor is to be explained as having originated on account of its biological advantage, and it is also not clear that the curvature of the embryo entails any effective biological disadvantage. I am inclined to think that the presence of a suspensor and also the simplification of the embryo by the omission of a suspensor may be better explained on morphological than on biological lines.

The alternative view, to which I incline, may be briefly stated. The presence of a suspensor of one or two tiers appears to be a fact of organization in a number of forms which are relatively primitive. Its presence may be looked upon as the last indication of the construction of the plant body from a filament or row of cells, i. e. as a juvenile stage in the development rapidly passed over and often suppressed. This juvenile stage may have suited the conditions of development and been retained and elaborated, as appears to have been the case in the line of descent leading to the Spermaphyta. On the other hand, the non-development of the suspensor may have allowed of useful changes in the primary orientation of the embryo, but its morphological significance appears to lie in the suppression of the last indication of the juvenile filamentous stage.

I do not propose to enter fully at present into the extended application of this way of regarding the suspensor. It may be pointed out, however, that it can be supported by analogies from the germination of spores of Algae, Bryophyta, and Pteridophyta, where a filamentous stage is often hurried over or suppressed. It also allows of application to the somewhat similar case of the presence of a cell taking no part in the further development, at the base of the sporogonium of the Jungermanniaceae, and its absence in the more direct development of the sporogonium of other Hepaticae.

One other feature of the construction of the embryo in the Filicales may be referred to in conclusion. This is the position of the primary or first root. Regarding this, Bower remarks: 'It is notable that though the root in Seed-Plants directly faces the suspensor, this is not the case in any Pteridophyte; in them it is always a lateral appendage, however nearly it may sometimes approach the centre of the hypobasal hemisphere. Accordingly it cannot be held to be itself the continuation of the primitive axis.' I do not propose to enter into the question as to how far this 
statement holds for the other phyla, but it does not seem to apply without considerable modification to the Filicales. It seems clear from Campbell's figures that the primary root is endogenous and practically median in the Marattiaceae even when, as in Danaea, a suspensor is present. What we know as to the initiation of the primary root in Helminthostachys suggests that the same holds here also, though the root subsequently appears lateral owing to the great development of the foot and the change in direction of the axis of the shoot. The direct continuation of the axes of the shoot and primary root is very striking in Lyon's figure of Botrychium obliquum.

It has been further pointed out above that the first root in Helminthostachys occupies a different position, relatively to the dorsiventral axis, from that occupied by the later roots, and this difference may have its explanation in the original polar position of this root as the continuation backwards of the primary axis of the plant. In this respect the relations in Helminthostachys appear closely comparable to those shown for the dorsiventral rhizome of the young plant of Polypodium vulgare in a figure by Professor Bower. ${ }^{1}$ There is thus some evidence for regarding the first root in the Filicales as different from the succeeding roots and potentially a main or tap-root. It would be comparable in not giving rise to the whole rootsystem to the primary root of a Monocotyledon. The position of the primary root-apex relatively to the suspensor in such a plant as Danaea is comparable to what is the rule in Gymnosperms, Dicotyledons, and Monocotyledons.

That such resemblances in the primary arrangement of the organs should be traceable between the Spermaphyta and the more primitive Filicales is of some interest and importance. It seems possible that the presence of a suspensor and the relative position of the organs of the embryo (including the terminal root with its apex directed towards the suspensor) may be characteristics of the higher plants that have persisted from the condition present in a filicineous ancestry. Proof is impossible in such a question, but it seems justifiable to state this view without asserting it to be the only or the complete explanation of the facts.

\section{Summary.}

I. The embryo of Helminthostachys extends down into the prothallus before segmentation takes place. The first two walls are transverse. Of the row of three cells, the one next the archegonial neck becomes the upper tier of the suspensor; it may remain undivided or become divided up into smaller cells. The next cell forms the second tier of the suspensor and becomes divided up into cells. The embryo proper is formed from the terminal cell of the filament.

2. The embryo proper is at first straight, continuing the line of growth

1 Land Flora, p. 214, Fig. I10. 
of the suspensor. It becomes differentiated into a hypobasal half from which the foot later arises, and an epibasal half from which the stem-apex, first leaf, and probably the first root, are formed. The apex arises near the centre of the epibasal tier.

3. With further growth the shoot becomes vertical and the axis of the embryo curved. Further development of the shoot gives rise to the hypocotyl bearing the first leaf and apex of the stem. The shoot is at first vertical, though dorsiventral in construction. Later its apex bends over and growth proceeds horizontally.

4. The relative positions of suspensor and embryo, and of the organs of the embryo, are compared for Marattiaceae, Ophioglossaceae, and SeedPlants, and it is suggested that the suspensor represents the last trace of the filamentous juvenile stage in development of the plant, and may have persisted in the Seed-Plants from their filicineous ancestry.

\section{DESCRIPTION OF FIGURES IN PLATE III.}

Illustrating Prof. Lang's paper on Helminthostachys.

All the figures are from untouched photographs.

Photo. I. Young embryo (e) still unsegmented but extending down into the prothallus; $f$, foot of plant on the same prothallus. $\times$ I 40 .

Photo. 2. Older arrested embryo showing the upper tier of the suspensor $\left(s^{1}\right)$, the second tier of the suspensor $\left(s^{2}\right)$, and the embryo proper $(e)$. The segment walls of the embryo are broken down, but a number of nuclei are visible. $\times 158$.

Photos. 3,4 . Two sections of a prothallus bearing a plant $\left(e^{1}\right)$, the younger embryo of intermediate age $\left(e^{2}\right)$, and the young arrested embryo $\left(e^{3}\right)$ figured in Photo. $2 . \quad s^{1}$, upper tier of suspensor of the intermediate embryo; $s^{2}$, second tier of suspensor. $\times 40$.

Photo. 5. Horizontal section of the embryo proper of $e^{2}$ more highly magnified. hyp, the hypobasal tier; $e p$, the meristematic epibasal tier. $\times{ }^{5} 5^{8}$.

Photos. 6-9. Four sections of the second intermediate embryo shown in Text-fig. 3, в. The junction of the second tier of the suspensor $\left(s^{2}\right)$, and the embryo proper $(e)$ is seen in Photo. 6 ; Photo. 7 shows the hypobasal half of the embryo proper giving rise to the foot. In Photo. 8 the base of the vascular cylinder is seen with the first tracheides $(t r)$. Photo. 9 passes through the apex of the stem which is marked with a cross. $\times I 5^{8}$.

Photo. Io. Obliquely transverse section of a mature embryo showing the well-preserved suspensor $\left(s^{1}, s^{2}\right) . \quad \times 40$.

Photo. I I. More highly magnified figure of this suspensor. $s^{1}$, upper tier; $s^{2}$, lower tier. $\quad \times \mathrm{I}_{5}^{8}$.

Photo. 12. Transverse section of a prothallus bearing a young plant attached by the suspensor, the two tiers of which are seen at $s^{1}$ and $s^{2} . \quad \times 40$.

Photo. I3. Section of the suspensor of another young plant in relation to the prothallus. Both tiers of the suspensor are multicellular. ar, archegonial neck; $s^{1}$, upper tier of suspensor; $s^{2}$, lower tier. $\times I^{8}$. 

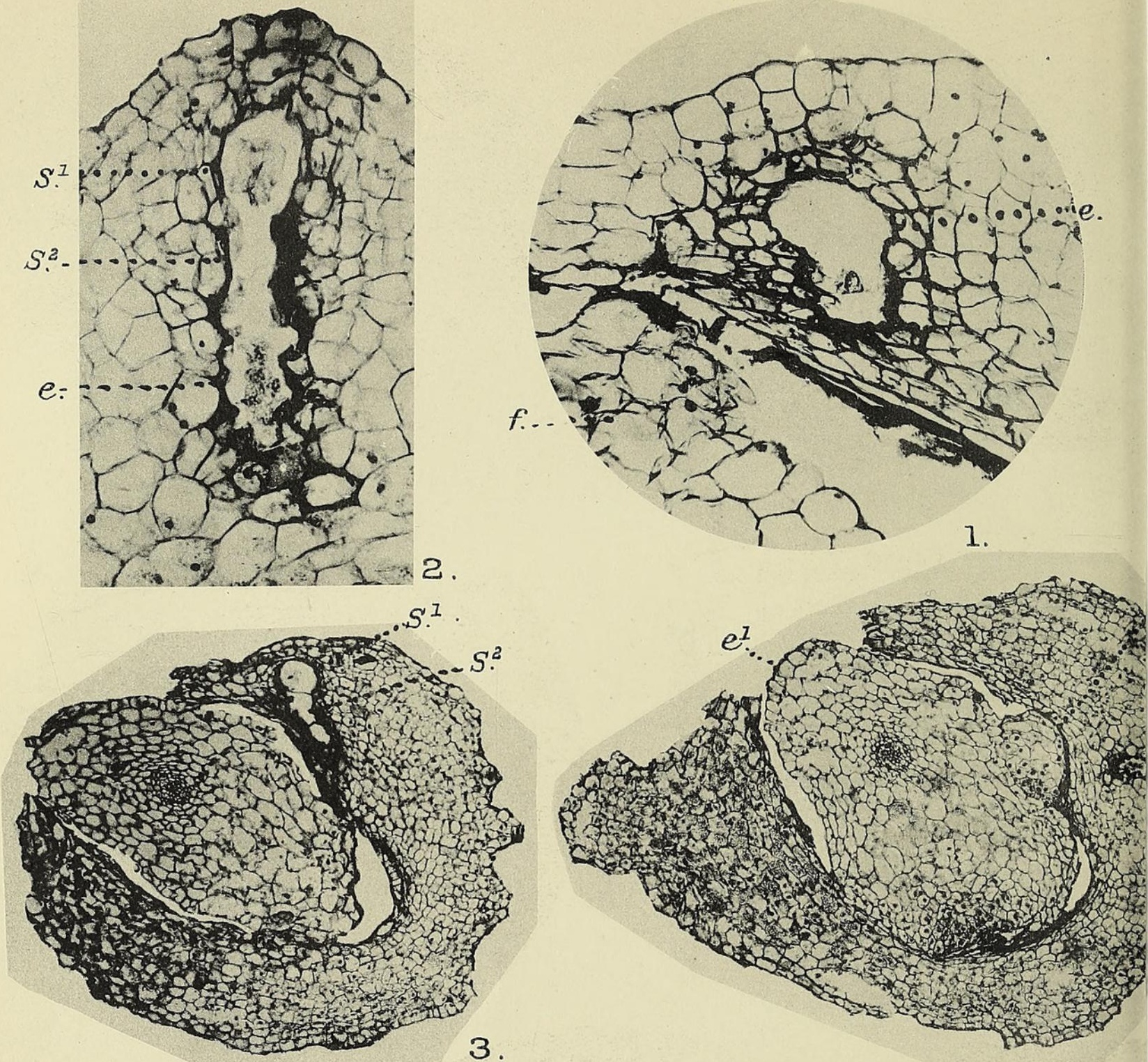

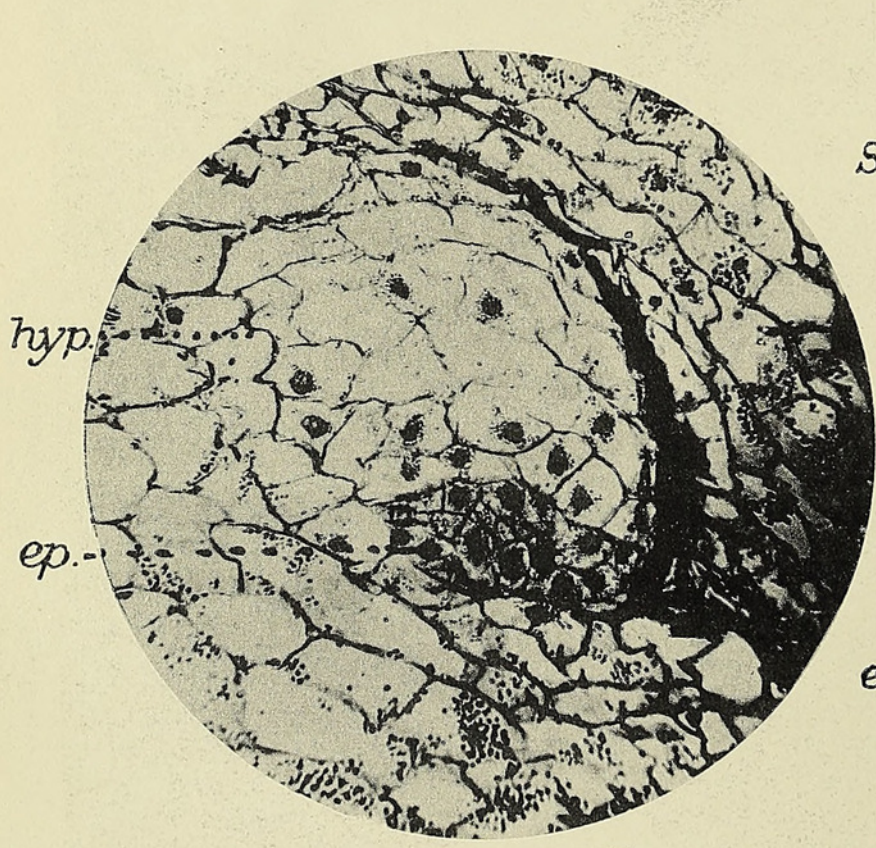

5
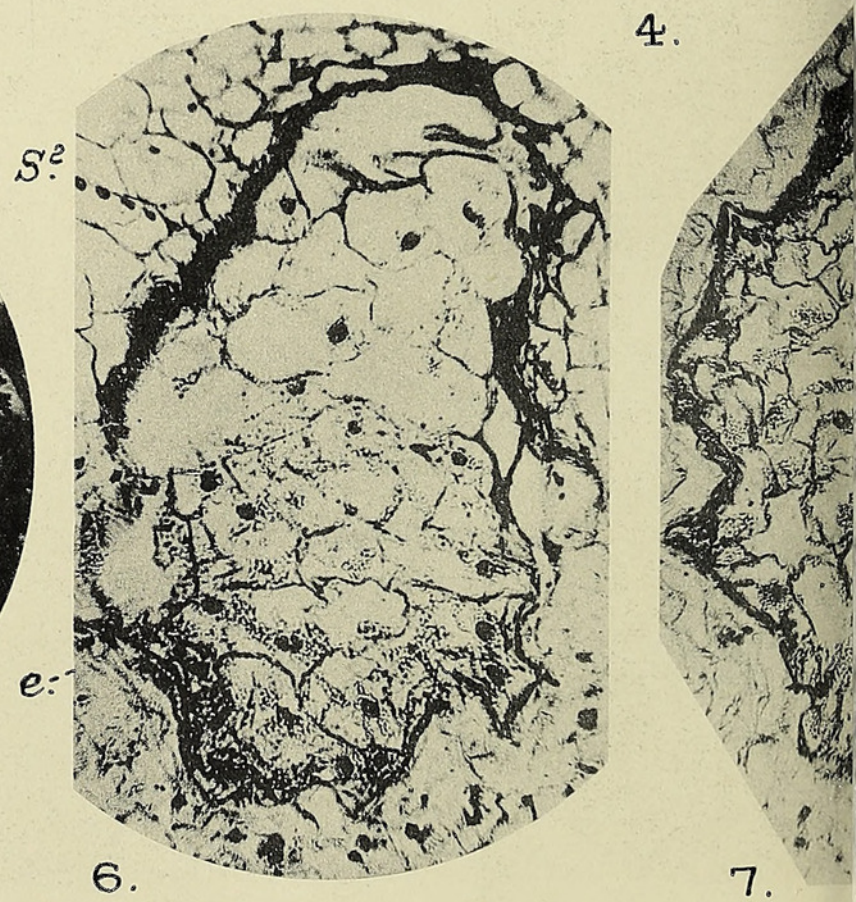

W.H.L.photo.

LANG - EMBRYO OF HELMINTHOSTACHYS. 


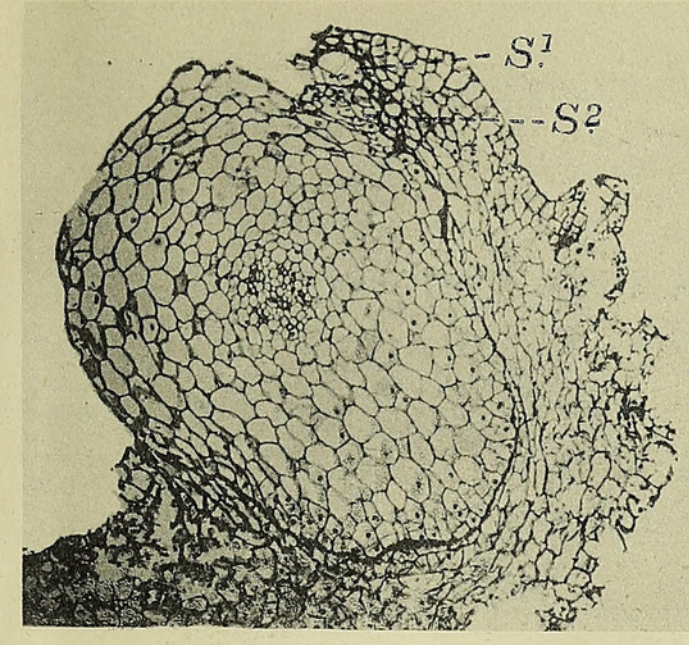

10.

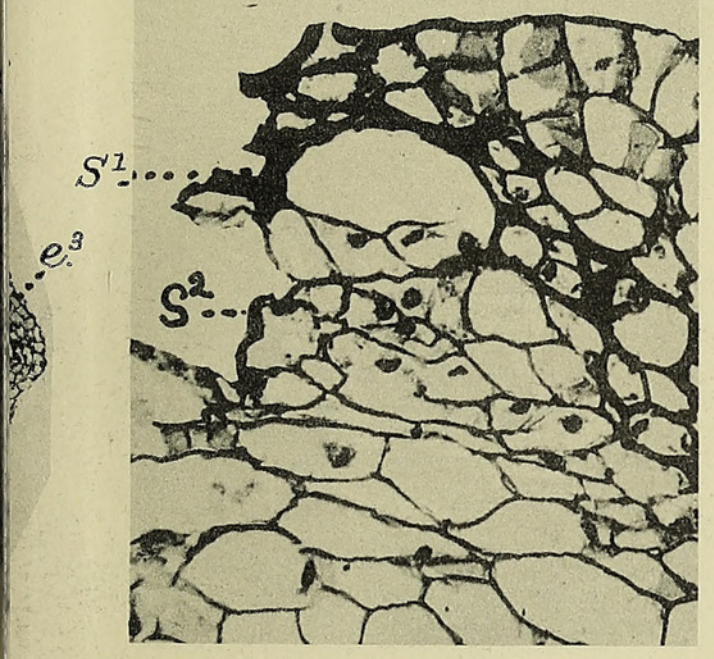

11.

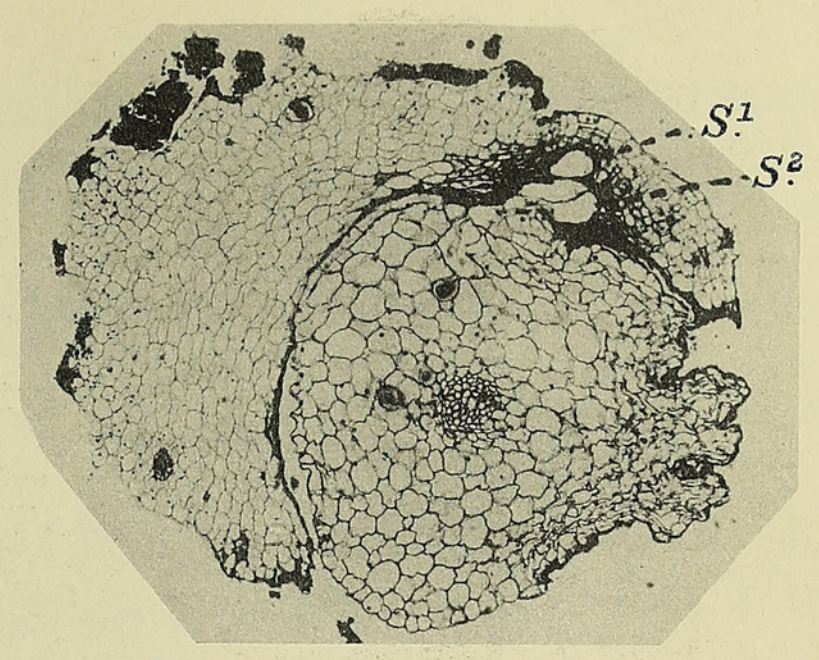

12.

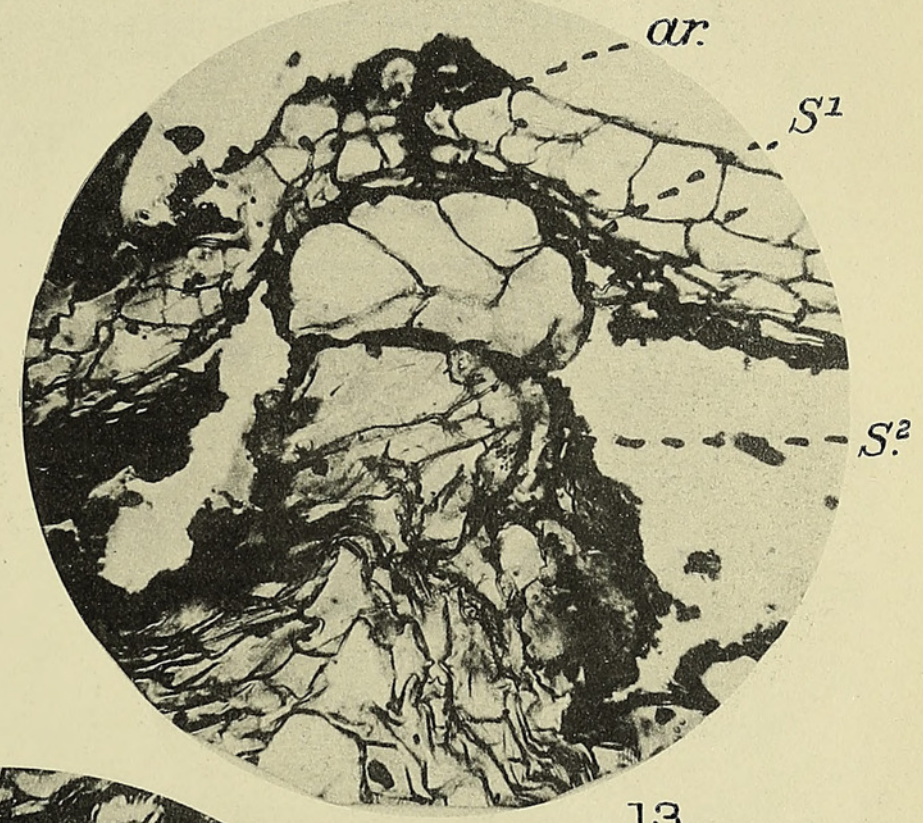

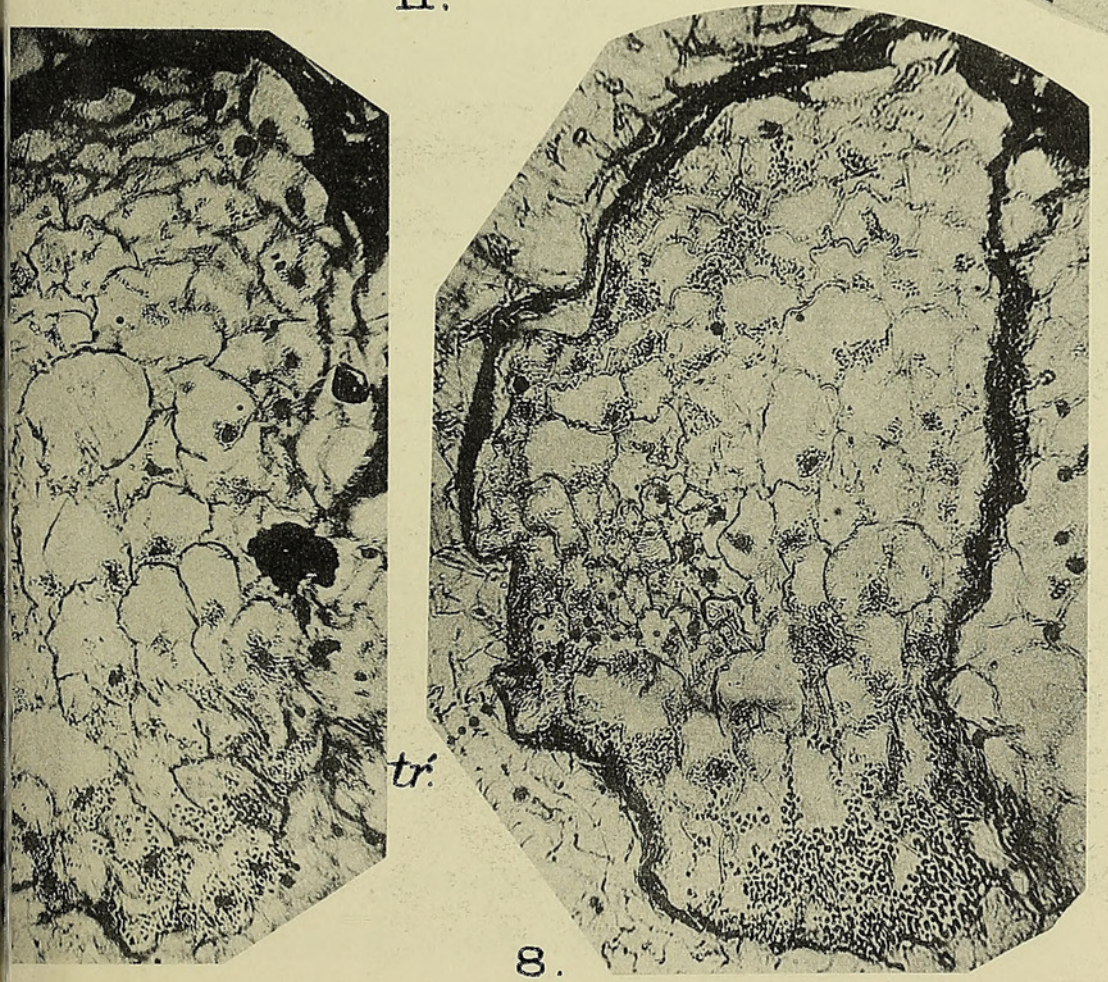

13.

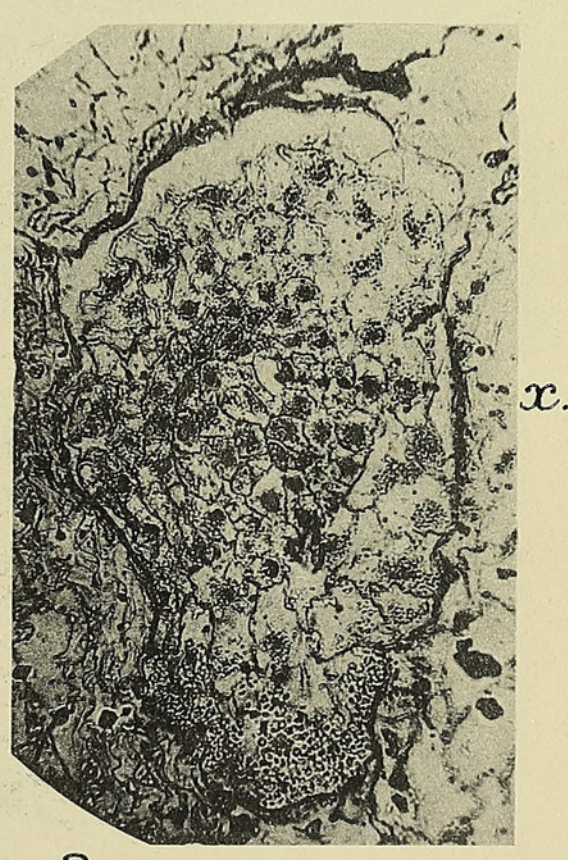

9.

Huth coll. 

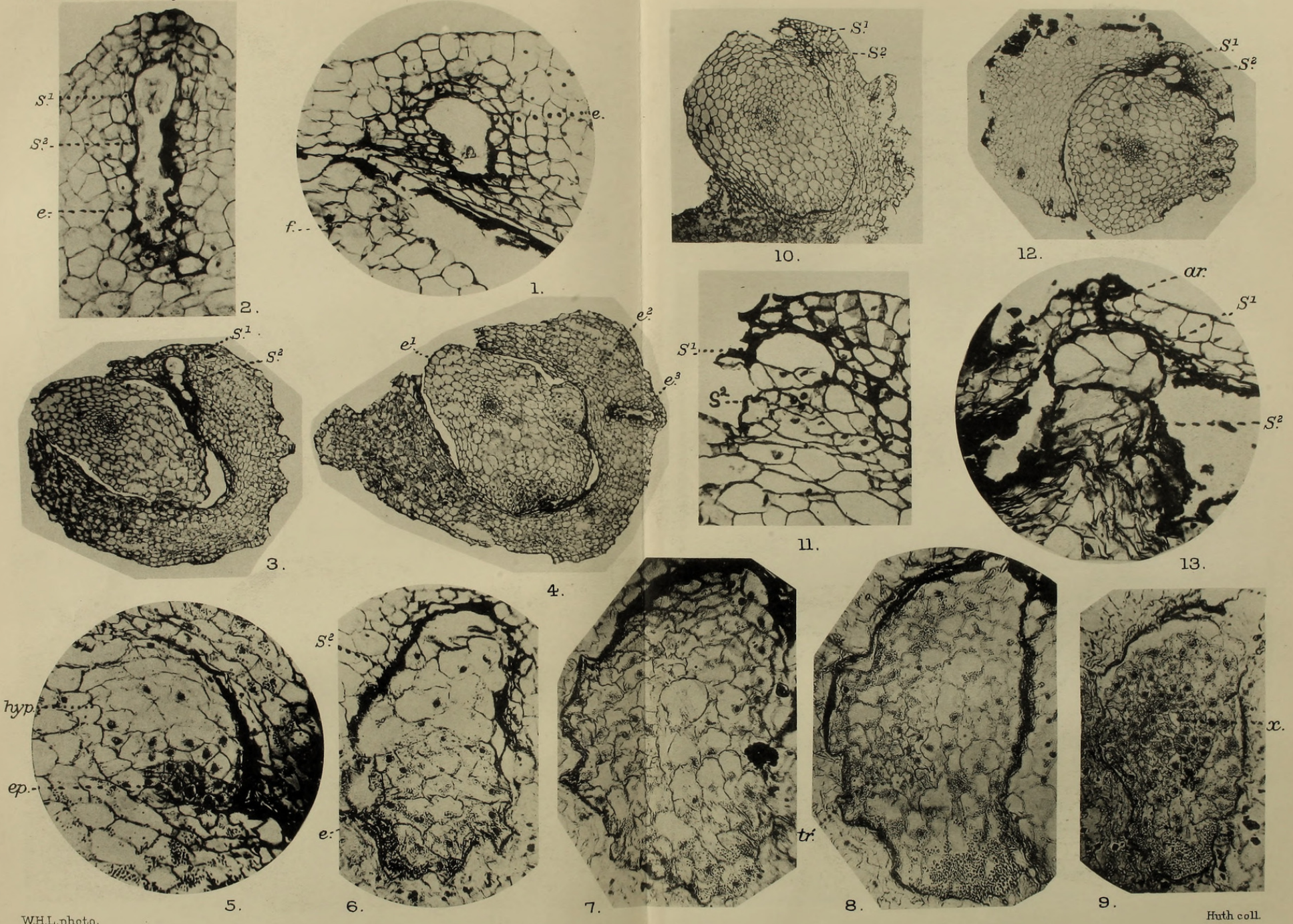


\section{$2 \mathrm{BHL}$ Biodiversity Heritage Library}

Lang, W. H. 1914. "Studies in the morphology and anatomy of the Ophioglossaceae. II. On the embryo of Helminthostachys." Annals of botany 28, 19-37. https://doi.org/10.1093/oxfordjournals.aob.a089495.

View This Item Online: https://www.biodiversitylibrary.org/item/236856

DOI: https://doi.org/10.1093/oxfordjournals.aob.a089495

Permalink: https://www.biodiversitylibrary.org/partpdf/320008

\section{Holding Institution}

Smithsonian Libraries

\section{Sponsored by}

Biodiversity Heritage Library

\section{Copyright \& Reuse}

Copyright Status: Not in copyright. The BHL knows of no copyright restrictions on this item.

This document was created from content at the Biodiversity Heritage Library, the world's largest open access digital library for biodiversity literature and archives. Visit BHL at https://www.biodiversitylibrary.org. 